\title{
Patrimônio: a alquimia do sangue indígena com a seiva africana e a verve do colonizador
}

\section{Raquel de Lourdes de Miranda e Silva Carmona ${ }^{1}$, Leandro de Almeida ${ }^{2}$, Jeane Odete Freire dos Santos Cavalcanti ${ }^{3}$ e Erika Patrícia Serafim Ferreira Bruns ${ }^{4}$}

${ }^{1}$ UNIESP Centro Universitário. Curso de Pós-Graduação em Ciências das Religiões, Diversidade e Ensino Religioso. Rodovia BR-230, km 14, s/no. Morada Nova. Cabedelo-PB (CEP 58109-303). E-mail: carmona.miranda@gmail.com.

${ }^{2}$ Secretaria de Educação. Universidade do Estado de Mato Grosso. Universidade Aberta do Brasil. Av. Tancredo Neves, 1095. Cavalhada III. Cáceres-MT, Brasil (CEP 78217-900).

${ }^{3}$ Universidade Federal da Paraíba. Centro de Educação. Programa de Pós-Graduação em Ciências das Religiões. Campus I. João Pessoa-PB, Brasil (CEP 58051-900).

${ }^{4}$ Universidad de Ciencias Empresariales y Sociales. Maestría en Ciencias Criminológico-Forenses. Paraguay 1401, C1061 ABA. Buenos Aires. Argentina.

Resumo. A etimologia da palavra patrimônio tem recebido novas expressões de maneira a atender a diversidade que representa ao longo dos anos, ampliando o seu conceito e criando uma nova dinâmica para falar em patrimônio artístico, histórico e cultural, além de material e imaterial. Esse artigo traz ênfase ao patrimônio cultural, no sentido de apresentar um texto com o objetivo de ampliar a discussão da Ciência da Religião Aplicada. Assim, foi traçada uma discussão voltada para aplicabilidade na sala de aula do Ensino Religioso ao falar de patrimônio e sociedade entrelaçados no campo da experiência, como preconiza a última Base Nacional Comum Curricular, de 2018. Também são somados esforços para evidenciar os princípios que alicerçam as epistemologias e pedagogias que norteiam o Ensino Religioso uma das cinco áreas de conhecimento que compõem os anos do Ensino Fundamental, por compreender que é parte da formação cidadã crítica, que respeita a diversidade religiosa e não aceita o proselitismo.

Palavras-chave: Patrimônio cultural; Ciência da Religião Aplicada; Ensino religioso.

Abstract. Heritage: The alchemy of indigenous blood with African sap and the verve of the colonizer. The etymology of the word heritage has received new expressions to meet the diversity it represents over the years, expanding its concept and creating a new dynamic to speak about artistic, historical and cultural heritage, as well as material and immaterial. This article
Recebido

$16 / 09 / 2020$

Aceito

$02 / 10 / 2020$

Disponível on line

$03 / 10 / 2020$

Publicado

31/12/2020

Acesso aberto

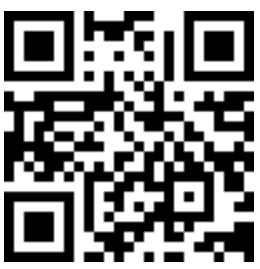

(D) 0000-0002-7192-3297

Raquel de Lourdes de

Miranda e Silva

Carmona

ISSN 2359-1412/RBGAS-2020-0140/2020/7/17/1/1071

Rev. Bras. Gest. Amb. Sustent.

http://revista.ecogestaobrasil.net 
emphasizes cultural heritage, in the sense of presenting a text to expand the discussion of the Science of Applied Religion. Thus, a discussion was drawn up for applicability in the religious education classroom when talking about heritage and society intertwined in the field of experience, as advocated by the last Brazilian Common Base National Curriculum, 2018. Efforts were also made to added to highlight the principles that underpin the epistemologies and pedagogies that guide the religious education - one of the five areas of knowledge that make up the years of elementary school, as it understands that it is part of critical citizen education, that respects religious diversity and does not accept proselytism.

Keywords: Cultural heritage; Applied Religious Studies; Religious education.
다 $0000-0002-8938-4180$

Leandro de Almeida

(1) 0000-0002-4864-1881

Jeane Odete Freire dos

Santos Cavalcanti

다 $0000-0001-7248-126 X$

Erika Patrícia Serafim

Ferreira Bruns

\section{Introdução}

A formação do cientista da religião que, dentre outras atribuições, inclui o espaço da sala de aula do ensino religioso, faz-se por meio da aplicação da Ciência Prática da Religião, como se refere Soares (2016) no texto que prefacia a Parte V do "Compêndio de Ciência da Religião: Ciência da Religião Aplicada" (Passos e Usarski, 2016), na qual Tworuschka (2016) escreve o capítulo "Ciência Prática da Religião: considerações teóricas e metodológicas". Quando se fala em Ciência da Religião Aplicada e, aqui vale lembrar que o uso da nomenclatura Ciência da Religião no singular é para manter a originalidade de Passos e Usarski (2016), organizadores do "Compêndio de Ciência da Religião". Tal obra é considerada um marco do referencial teórico nos estudos da Área no Brasil. Portanto, optou-se por assim utilizar, embora se compreenda o uso da denominação plural por alguns programas de graduação e pós das universidades brasileira, principalmente as públicas. Portanto, não significa se remeter a um debate que acontece no âmbito do entendimento iluminista por diferenciar-se uma ciência pura do seu modelo aplicado, mas apresentar uma contribuição real, palpável e concreta do trabalho de um cientista da religião no exercício da sua profissão.

Por outro lado, falar de patrimônio quase sempre é referir-se ao exótico, ao colecionismo, ao mercado da arte e de antiguidades ou afins. No entanto, o que se pretende no desenvolvimento desse texto é fornecer subsídios que despertem para a pesquisa, uma vez que é de fundamental importância para a salvaguarda do patrimônio cultural brasileiro religioso ou não e, nesse sentido, é compreender que Patrimônio Cultural é como afirma Pinto (2016), aquilo que se quer legar às gerações vindouras, a partir de um lugar de fala, de um discurso político que privilegia o coletivo, sobretudo, enquanto grupo social coeso, conscientes e críticos.

Noutro panorama, a discussão acerca do patrimônio cultural sob o enfoque do ER como uma propositura preconizada na BNCC (Brasil, 2018), que assinala ser premissa dessa disciplina própria do Ensino Fundamental: "[...] tratar os conhecimentos religiosos a partir de pressupostos éticos e científicos, sem privilégio de nenhuma crença ou convicção." (Brasil, 2018, p. 436). 0 que significa abeirar-se desses conhecimentos tendo como bases as diversas culturas e tradições religiosas, levando em consideração as filosofias seculares de vida e, nesse lugar o patrimônio cultural encontra seu berço pelas materialidades e imaterialidades contextualizadas nas tradições religiosas. 


\section{Conceituando o patrimônio}

É possível traçar duas ideias que se cruzam para falar do conceito de patrimônio: a primeira se remete aos bens que são transmitidos aos herdeiros e descendentes, podendo ser materiais que possuem valor monetário (casas, joias, terras, objetos de arte etc.), podendo ser avaliado pelo mercado que vai estipular um valor comercial, ou ainda, aquele que possui pouco valor monetário, mas grande valor afetivo e lembrar a sua ancestralidade (fotografias, cartas, diários, imagens, uma imagem religiosa ou até mesmo um bem de uso pessoal etc.). Esses itens podem fazer parte de uma herança ou testamento de um indivíduo (Funari e Pelegrini, 2006). Nesse sentido, pode ser dito que "etimologicamente, a palavra "patrimônio" aponta para a linhagem patriarcal, para o que de mais identitário tem a cultura ocidental: a progenitura - literalmente, "patrimônio" quer dizer 'herança paterna'” (Pinto, 2016, p. 639).

Além desses tipos de patrimônio destacados, pode se considerar o patrimônio espiritual ou imaterial, que são aqueles provenientes dos saberes das comunidades tradicionais e conhecimentos que são passados de geração a geração, além das infinidades de ensinamentos e lições de vida (Funari e Pelegrini, 2006). Estes constituem tanto como patrimônio individual, como por exemplo, a vastíssima obra (literárias, desenhos, pinturas etc.) que traduz o conhecimento peculiar de Ariano Suassuna, autor paraibano, radicado no Município de Recife (PE), que dentre outras sensíveis e de caráter regionalista, escreveu o Auto da Compadecida (Suassuna, 2005), imortalizada na minissérie (1998), da Rede Globo de Televisão, e posterior filme (1999), Globo Filmes, sob a direção de Guel Arraes.

Já o patrimônio coletivo como a nomenclatura dispõe, é um bem de uma comunidade, localidade, ou de dimensões nacionais. Por assim compreender, Funari e Pelegrini (2006) chamam a atenção para o fato de que há aqui uma multiplicidade de pontos de vista, de interesses políticos, religiosos, sociais, econômicos. Sobretudo ao considerar a subjetividade do valor do patrimônio coletivo. Uma lapinha pode não ser considerada patrimônio para uns, ao mesmo tempo em que se apresenta sensivelmente importante para um determinado grupo ou época, por exemplo.

No âmbito do patrimônio coletivo, será na Idade Média, com a presença do cristianismo em boa parte da Europa, que se acrescenta o caráter simbólico e coletivo do religioso. Desde o culto aos santos, a venda de relíquias, as peregrinações aos lugares sagrados do catolicismo romano constituem-se em ações que mostrarão a singularidade coletiva na valorização de lugares, objetos, rituais e práticas coletivas (Funari; Pelegrini, 2006). Para Pinto (2016), será a partir da formação dos Estados Modernos com a ascensão da burguesia e fim do feudalismo e posterior conhecimento da república, sobretudo no contexto francês, que o conceito de patrimônio (nacional) será compreendido de modo mais enfático.

Em 1819, no Ministério do Interior francês, surgia um gabinete dedicado aos monumentos históricos. As primeiras classificações teriam lugar em 1840, com 934 monumentos elencados e protegidos, que iam cronologicamente desde a pré-história ao século XVI (Pinto, 2016). Por outro lado, persiste a própria legitimação do nascente e em plena afirmação, Estado Moderno. O campo das antiguidades, da redescoberta dos monumentos e, de seguida, das populações e culturas pré-cristãs e medievais, vai tornarse um campo da maior importância na criação de narrativas de legitimação de poder (Pinto, 2016, p. 640). Por este entendimento, na questão que respeita os espaços das classes sociais e a complexidade do patrimônio que representa cada uma delas.

Não é difícil encontrar a defesa do barroco, por exemplo, como uma arte de grande expressão em detrimento da arte popular ou o patrimônio das camadas populares. Aqui, é salutar compreender o papel dos órgãos de defesa do patrimônio, seja em quaisquer instâncias - mundial, nacional, estadual e municipal. Em comum, o Município de Olinda, no

Rev. Bras. Gest. Amb. Sustent., 2020, vol. 7, n. 17, p. 1071-1079. 
Nordeste do Brasil, a Grande Muralha chinesa, a cidade pré-colombiana de Machu Picchu, da Civilização Inca do Peru, o Palácio de Versalhes na França, a Acrópole de Atenas, na Grécia, e o Centro Histórico de Florença, na Itália, possuem o fato de serem considerados Patrimônio da Humanidade, segundo a Organização das Nações Unidas para a Ciência e a Cultura (UNESCO). 0 que significa dizer que são exemplares importantes para as sociedades que as construíram e que fazem parte de um conjunto significativo para o mundo.

Neste sentido, vale observar que a Convenção do Patrimônio Mundial Cultural e Natural, adotada a partir de 1972 pela UNESCO, possui como objetivo principal a preservação de bens culturais e naturais considerados expressivos para a humanidade (Brasil, 2014). Assim, constitui-se como "[...] um esforço internacional de valorização de bens que, por sua importância como referência e identidade das nações, possam ser considerados patrimônio de todos os povos" (Brasil, 2014).

Por este entendimento, associa-se, sobremaneira, o conceito de patrimônio à questão da materialidade, mas a UNESCO também se preocupa com a preservação do patrimônio imaterial. Ou seja, aquele que é sentido, absorvido, passado por gerações, embora não seja necessariamente materializado. É a música, a dança e o modo de fazer as coisas, são as tradições culturais presente nas manifestações dos povos em todas as sociedades, através do tempo e nos mais diversos lugares. Tome-se como exemplo o "fado" português, que desde a mais sonora voz de um fadista cantado nas tascas e bares lisboetas aos mais sofisticados palcos do mundo, é uma expressão musical portuguesa que foi tombada como patrimônio imaterial da humanidade e, por assim dizer, não só de Portugal, mas do mundo (UNESCO, 2011). Outra expressão musical portuguesa, também reconhecida, foi o "cante alentejano", que é uma forma de cantar bastante peculiar da região do Alentejo. São expressões musicais tocantes, pungentes e emocionantes para quem a ouve e de inestimável valor para quem o produz independentemente de onde se tenha nascido (UNESCO, 2014).

É importante considerar o que a Organização das Nações Unidas, por meio da UNESCO mostra a preocupação com o Patrimônio da Humanidade, mas é preciso deixar claro o que entende como patrimônio Cultural, seja material ou imaterial e Patrimônio Natural. Assim, Patrimônio Cultural é composto por monumentos, grupos de edifícios ou sítios que tenham valor universal excepcional do ponto de vista histórico, estético, arqueológico, científico, etnológico ou antropológico. Incluem obras de arquitetura, escultura e pintura monumentais ou de caráter arqueológico e ainda, obras isoladas ou conjugadas do homem e da natureza.

Ao correr o risco de parecer reducionista, pode ser dito que são denominados Patrimônio Natural as formações físicas, biológicas e geológicas excepcionais, habitats de espécies animais e vegetais, principalmente aquelas ameaçadas ou em extinção e áreas que tenham valor científico, de conservação ou estético excepcional e universal. No mesmo sentido, o Patrimônio Imaterial contempla os saberes, práticas, representações, expressões, conhecimentos e técnicas - com os instrumentos, objetos, artefatos e lugares culturais que lhes são associados e atribuídos, ou seja, localidades específicas que as comunidades, os grupos e, em alguns casos, os indivíduos reconhecem como integrante de seu patrimônio cultural.

Uma das formas de proteção dessa porção imaterial da herança cultural é a Convenção para a Salvaguarda do Patrimônio Cultural Imaterial, adotada pela UNESCO em 2003 (Brasil, 2014). Pelo exposto, crer-se que já estão assentados os conceitos de patrimônio, que grosso modo, pode ser entendido como um conjunto significativo de um lugar, de um povo, de uma sociedade. No entanto, essa discussão mais ampla acerca desse conceito tem adquirido uma nova dinâmica e atingido contornos diferenciados. Isso, porque novos parâmetros foram traçados e de acordo com as vozes de Funari e Pelegrini (2006), o século XX, sobretudo nas últimas décadas, superou o conceito reducionista e 
elitista de patrimônio histórico e artístico para se tornar em cultural, principalmente a partir da década de 1980, quando a concepção dessa terminologia vai além da produção artística.

Por fim, essa dinâmica mais ampliada vai englobar como definição de patrimônio, a relação de patrimônio material e imaterial e observar a criação de cenários, ainda que muitos se constituam como artificiais, que são delineados pelos interesses econômicos, rendidos ao turismo, que transformam cidades, monumentos históricos e festejos (quase sempre religiosos) em produtos de consumo. No entanto, o que não foi falado, mas que é pertinente para o contexto, é a importância da preservação, restauro e conservação "[...] do nosso patrimônio como um todo, seja ele histórico, artístico, cultural ou ambiental, móvel ou imóvel, que são tratados como conquistas irrevogáveis no âmbito da preservação do patrimônio inatingível" (Spina e Serratto, 2015, p. 116).

Saliente-se que no Brasil, os estudos sobre patrimônio, bem como a sua defesa, tem sido assimilada e por vezes a burocracia que envolve os órgãos na questão preservacionista está no papel que é desempenhado por cada um. Também, é importante dizer que a multidisciplinaridade tem contribuído com a coletividade na validação da sua herança histórico-cultural, o que vem de certa forma, alterando positivamente alguns aspectos da educação formal.

\section{Sobre patrimônio e religião}

O século XX, denominado por Hobsbawm (1997) como a "era dos extremos", ou o "breve século" pela efervescência trazida por duas guerras de caráter mundial e mudanças significativas nas sociedades, sobretudo ocidentais, vai trazer novos olhares sobre o passado, além de acalentar a ideia do que é patrimonializável, possui uma conotação ideológica. Nos regimes totalitários como os fascistas, nacional-socialistas e comunistas, é bem mais palpável a formatação dos indivíduos por meio da sua história e do seu patrimônio, ou seja, daquilo que é herdado dos seus antepassados.

Neste lugar, encontrar expressões como Belas Artes, Altas Artes, fine arts será bastante comum, principalmente ao se levar em conta a proposta de intelectuais e governantes como André Malraux, ministro da cultura da França entre os anos de 1958 e 1969, que considerou e, em algum momento pôs em prática a inventariação dos bens do governo francês (Pinto, 2016). A partir do final da II Guerra e a difusão de pensamentos como o de Malraux, alçaram o patrimônio a um lugar do qual não mais vai sair como considera Pinto (2016), que é o da educação. Em outras palavras: se o patrimônio significava herança, então, nada mais prestável ao papel de educar jovens para a sua herança cultural do que direcionar esse olhar para as coleções dos museus e monumentos que representavam as classes abastadas.

Neste modelo, o patrimônio é artístico e se traduz naquele que desconsiderava a cultura popular, embora por outro lado, evidenciasse bom tratamento para o patrimônio religioso. Assim, considera-se que:

Diversos autores já chamaram a atenção para o papel basilar que a religião desempenhou na consolidação da ideia de patrimônio, ao menos no Ocidente. Uma narrativa arquetípica das origens institucionais do patrimônio francês conta que o termo "vandalismo" teria sido forjado pelo abade Grégoire para se referir à destruição de igrejas católicas durante a Revolução Francesa, movimento que deu origem à primeira Comissão dos Monumentos Históricos daquele país. Entre os revolucionários, os sentimentos anticlericais (combinados aos antimonárquicos) não se mostraram incompatíveis com o reconhecimento do papel da Igreja Católica como repositório da memória nacional (Lins et al., 2017, p. 10). 
No panorama nacional brasileiro a arquitetura religiosa colonial católica será exponencialmente cuidada como repositório da memória nacional, ou pelo menos boa parte dela. As autoras assinalam que há um volume expressivo de tombamentos de bens católicos em relação a outros não religiosos (Lins et al., 2017).

Uribarren (2018) chama atenção para o fato de que o Instituto do Patrimônio Histórico e Artistico Nacional (IPHAN), desde a sua criação, vai supervalorizar o aspecto religioso do período colonial e atribuir valor artístico ao Barroco religioso. Regra geral, tal benefício produziu o que Chuva (2008) apontou como "monumentalização da fé", considerando a hegemonia do catolicismo no território brasileiro. A partir da ampliação das fronteiras do que é patrimônio na concepção do IPHAN e a absorção da imaterialidade nesse contexto, bem como o reconhecimento das tradições populares, pode ser dito que sagrado e patrimônio serão alavancados a partir do decreto presidencial de 2000, que criou o Programa Nacional do Patrimônio Imaterial que passa a catalogar e proteger os muitos aspectos dessa imaterialidade, incluindo os rituais populares religiosos, festas, vestimentas, alimentos e outras manifestações indizíveis da experiência religiosa plural da diversidade brasileira.

Mediante o avanço que esse reconhecimento traz, o espaço para a diversificação de instituições religiosas reconhecidas na listagem dos bens de valor nacional se amplia ainda mais, dando lugar a imaterialidade e em alguns casos a materialidade, como no tombamento de alguns terreiros de candomblé. Giumbelli (2008) assinala que a partir dos anos 1980 do século XX, há um movimento contrário à hegemonia, que vai redundar no reconhecimento público das religiões afro-brasileiras, sobretudo, as suas contribuições no que diz respeito aos aspectos culturais, porém não sem dor e nem que isso seja considerado fácil, uma vez que parte da sociedade ainda insiste em negar suas raízes e mesmo no campo das religiões haja tentativa de branquear santos negros e/ou trabalhar na efetivação de uma sincretização favorável ao catolicismo.

Neste entendimento, o contexto preservacionista das religiões afro-brasileiras até os dias de hoje, resulta das transformações ocorridas no próprio campo religioso brasileiro, assumidamente plural, embora o reconhecimento que traz o respeito pela diversidade seja ainda um custo alto que deve ser arcado pela educação e, sem o qual dificilmente a sociedade avança, sendo traçado na busca do seu lugar no espaço público, que dá visibilidade aos novos atores e consolida ações de empoderamento, longe de como deveria ser, mas com mudanças efetivas nesse contexto.

\section{O que a BNCC tem a ver com isso?}

A importância da Base Nacional Comum Curricular para os estudos de Ciências das Religiões, como disciplina efetivada no Ensino Fundamental, nomeadamente se dá, quando o ensino religioso deixa de ser "aula de religião" para trabalhar a diversidade da sociedade brasileira, seus valores culturais e seu coro polifônico de religiões, dentre os muitos componentes que auxiliam a formação cidadã, além de afastar o proselitismo e a confessionalidade da sala de aula. Portanto, a BNCC é "[...] um documento normativo que define o conjunto de aprendizagens essenciais que todos os alunos devem desenvolver ao longo das etapas e modalidades da Educação Básica" (Brasil, 2018). Sendo uma prerrogativa válida para todas as disciplinas pertinentes ao nível de ensino.

É válido que se referencie que a BNCC é construída para atender as demandas diferenciadas por níveis de ensino e no caso do ensino religioso, está contemplado no Ensino Fundamental, primeiros e últimos anos, embora unidades temáticas cujos objetos de conhecimento são as memórias, as narrativas míticas e as narrativas religiosas, a oralidade, os ritos, os símbolos, a ancestralidade, tradição e mitos, por exemplo, possam ser vistos do $1^{\circ}$ ao $6^{\circ}$ anos e permitam trabalhar o assunto patrimônio cultural - material e imaterial. Trata-se de estabelecer abordagens voltadas para o ensino do respeito à 
diversidade, com valores fincados na alteridade que enxerga o patrimônio a partir do desenvolvimento das habilidades dialogando no espaço da pluralidade inclusiva.

Referir-se à essencialidade da BNCC é referendar a importância do ensino religioso e contextualizar os estudos de patrimônio a partir da educação inicial que é o lugar do Ensino Fundamental. Tome-se, por exemplo, o fato de que apesar de no Brasil não existir uma religião oficial, uma vez que a laicidade é garantida constitucionalmente, pode ser lida no preâmbulo da Constituição Federal (1988) a expressão: "sob a proteção de Deus", que mesmo sem força normativa, certamente inibe a manifestação das religiões "não cristãs". Outro exemplo que pode falar da urgência de tornar evidente a diversidade da sociedade brasileira diz respeito a questão da inventariação dos bens no âmbito do patrimônio material ou imaterial. Ou seja:

No inventário mineiro, apresentado na obra Devoção e Arte - imaginária religiosa em Minas Gerais, organizada pela professora, restauradora Beatriz Coelho (2017), pela editora Edusp, se constitui como um grande referencial para as pesquisas iconográficas, sobretudo do(s) barroco(s) ibérico, iberoamerica, e nacional. No capítulo dedicado à iconografia, dentre os santos populares, São José está no $4^{\mathrm{o}}$ lugar com a quantidade de 70 imagens, ficando atrás apenas, de Santo Antônio, Nossa Senhora do Rosário e Nossa Senhora das Dores (Carmona, 2019, p. 92).

A questão crucial orbita em torno das imagens presentes nos terreiros de candomblé, os objetos sagrados, comidas e as indumentárias do povo de terreiro que pouco ou nenhuma vez se vê representado em um inventário. Apesar de já o IPHAN reconhecer e proceder tratamento adequado às outras religiões não cristãs, o "grosso" continua a ser cristão e predominantemente católico. Aqui o que menos se pretende é entrar na seara de uma sociedade herdeira do colonialismo patriarcal, católico, branco e genocida, que desmereceu as tradições dos negros escravizados e sufocou os saberes indígenas. Não que sejam considerações atiradas ao esquecimento, ao desmerecimento, mas, porque a complexidade do tema exige maior aprofundamento, além do diálogo proposto nesse artigo, perpassa a discussão do patrimônio no âmbito escolar segundo o modelo contemplado na BNCC no tocante do ensino religioso.

A urgência de se trabalhar o respeito pela diversidade religiosa tanto se dá no registro de tradições que por vezes apenas a oralidade consegue mostrar, bem como por priorizar bens contemplados na leitura das diversidades brasileiras. Carmona (2019, p. 96) chama a atenção acerca disso, ao apontar que "muito deve o Brasil e as artes brasileiras a Mario de Andrade (1893-1945), que lançou Macunaíma, publicou os Aspectos das artes plásticas no Brasil (1928) contendo um ensaio denominado 'O Aleijadinho'” Andrade (1986). Nesse caso, a autora assinala que Mário Andrade empreendeu missões Brasil afora, chegando ao Nordeste em 1938. Tais expedições permitiu que presenciasse manifestações populares de cultura, arte popular e religiosidades.

Acerca desses eventos, foram gravados e compilados no acervo documental do Instituto do Patrimônio Histórico e Artístico Nacional (IPHAN), repartição da qual o autor era funcionário. Também é de Andrade (1986), o pensamento que dá origem ao título desse texto "a alquimia do sangue indígena com a seiva africana e a verve do colonizador", ao referir-se a monumental obra do mestre-escultor mineiro Antônio Francisco Lisboa, o popular "Aleijadinho", filho de escrava com branco, é mestiço e possui escravos que trabalham na sua oficina. A importância dessas palavras mora nos aspectos estéticos da iconologia barroca representada no conjunto da obra de Aleijadinho que mostra os traços afro-indígenas da imaginária barroca mineira, que hoje é patrimônio nacional e mostra uma leitura mestiça dessa estética tipicamente brasileira. 


\section{Considerações finais}

É palpável a contribuição de um parâmetro curricular que possui uma base comum nacional que respeite as especificidades locais e regionais no contexto de uma educação pela diversidade, sobretudo quando essa base é a BNCC mais recente (2018) e contempla o Ensino Religioso não proselitista e laico. Compreendendo que a laicidade do Estado significa a não confessionalidade, não opta e não escolhe uma religião, mas respeita a diversidade religiosa.

0 reconhecimento da formação do professor de Ensino Religioso como o profissional oriundo das Ciências das Religiões, também é um fato conclusivo. Não apenas pela sua formação servir a uma epistemologia que valida o seu saber fundamentado no pensamento acadêmico que acontece em oposição ao conhecimento teológico cristão cuja valorização de pressupostos cristocêntricos turva a pluralidade nacional e desrespeita a cidadania que é pertinente a uma sociedade democrática.

Por fim, a multidisciplinaridade das Ciências das Religiões é também um olhar diferenciado na defesa do patrimônio cultural - material e imaterial, por compreender as manifestações religiosas que encerram símbolos, mitos, ritos e muitas outras particularidades, haja vista que é o conhecimento religioso o essencial objeto da área de ensino religioso, diferentemente do que se pensa de modo errado como sendo as religiões.

Este conhecimento religioso, produzido no âmbito da multidisciplinaridade das Ciências das Religiões, detém-se na investigação da manifestação fenomenológica da religião nas mais diferentes culturas e sociedades. Assim, aquilo que é inerente ao ser humano, o sentido da vida, o enfrentamento das adversidades, as alegrias e celebrações comemorativas e a morte passam a ser temáticas em torno das quais se as sociedades produzem e manifestam as cosmovisões, mitologias, ritos, saberes, tradições, crenças, narrativas, universos simbólicos, práticas, linguagens e outras múltiplas manifestações que formam o substrato cultural da humanidade, onde tem lugar o patrimônio.

\section{Conflito de interesses}

Os autores declaram não haver conflitos de interesses.

\section{Referências}

Andrade, M. ("O Aleijadinho"): aspectos das artes plásticas no Brasil. 3. ed. Belo Horizonte: Itatiaia, 1984.

Brasil. IPHAN. Patrimônio Nacional. 2014. Disponível em: <http://portal.iphan.gov.br/pagina/detalhes/24>. Acesso em: 20 jan. 2020.

Brasil. Ministério da Educação. Base Nacional Comum Curricular (BNCC). Brasília: MEC, 2018. Disponível em: <http://basenacionalcomum.mec.gov.br/images/ BNCC_EI_EF_110518_versaofinal_site.pdf $>$. Acesso em: 20 jan. 2020.

Carmona, R. L. M. S. Lá onde o santo perdeu as botas: iconografia e imagem sacra em São José. João Pessoa: Universidade Federal da Paraíba, 2019. (Dissertação de mestrado).

Chuva, M. Os arquitetos da memória: sociogênese das práticas de preservação do patrimônio cultural no Brasil. Rio de Janeiro: Editora UFRJ, 2009.

Coelho, B. (Org.). Devoção e arte: imaginária religiosa em Minas Gerais. São Paulo: EDUSP, 2017.

Funari, P. P.; Pelegrini, S. C. A. Patrimônio histórico e cultural. Rio de Janeiro: Jorge Zahar Editor, 2006. 
Hobsbawm, E. J. Era dos extremos: o breve século XX: 1914-1991. São Paulo: Companhia das Letras, 1995.

Lins, P.; Gomes, E.; Machado, C. Religião, patrimônio e modernidades plurais. Religião \& Sociedade, v. $37, \quad$ n. $3, \quad$ p. $9-16, \quad 2017 . \quad$ https://doi.org/10.1590/010085872017v37n3editorial

Passos, J. D.; Usarski, F. Compêndio de Ciência da Religião. 1. reimp. São Paulo: Paulinas \& Paulus, 2016.

Pinto, P. M. Ciência da Religião aplicada ao patrimônio cultural. In: Passos, J. D.; Usarski, F. Compêndio de Ciência da Religião. São Paulo: Paulinas \& Paulus, 2016.

Soares, A. M. L. Ciência da Religião aplicada à Teologia. In: Passos, J. D.; Usarski, F. Compêndio de Ciência da Religião. 1. reimp. São Paulo: Paulinas \& Paulus, 2016.

Spina, G. L.; Serratto, E. B. F. Patrimônio histórico e cultural: uma revisão bibliográfica. Educação, v. 5, n. 3, p. 99-116, 2015.

Suassuna, A. Auto da compadecida. 35. ed. Rio de Janeiro: Agir, 2005.

Tworuschka, U. Ciência Prática da Religião: considerações práticas e metodológicas. In: Passos, J. D.; Usarski, F. Compêndio de Ciência da Religião. 1. reimp. São Paulo: Paulinas \& Paulus, 2016.

UNESCO - Organização das Nações Unidas para a Educação, a Ciência e a Cultura. Intagible Cultural Heritage. Fado, urban popular song of Portugal. 2011. Disponível em: <https://ich.unesco.org/en/RL/fado-urban-popular-song-of-portugal-00563>. Acesso em: 20 jan. 2020.

UNESCO - Organização das Nações Unidas para a Educação, a Ciência e a Cultura. Intagible Cultural Heritage. Cante Alentejano, polyphonic singing from Alentejo Southern Portugal. 2014. Disponível em: <https://ich.unesco.org/en/RL/cantealentejano-polyphonicsinging-from-alentejo-southern-portugal-01007>. Acesso em: 20 jan. 2020.

Uribarren, M. S. Germain Bazin e o IPHAN: redes de relações e projetos editoriais sobre o barroco brasileiro. Revista CPC, v. 13, n. 25, especial, p. 108-134, 2018. Disponível em: <http://www.revistas.usp.br/cpc/article/view/141837/147384>. Acesso em: 25 mar. 2020.

Informação da Licença: Este é um artigo Open Access distribuído sob os termos da Licença Creative Commons Attribution, que permite uso irrestrito, distribuição e reprodução em qualquer meio, desde que a obra original seja devidamente citada. 